\title{
Digital Resource Sharing and Library Consortia in Italy
}

Interlibrary cooperation in Italy is a fairly recent and not very widespread practice. Attention to the topic was aroused in the eighties with the Italian library network project. More recently, under the impetus toward technological innovation, there has been renewed (and more pragmatic) interest in cooperation in all library sectors. Sharing electronic resources is the theme of greatest interest today in university libraries, where various initiatives are aimed at setting up consortia to purchase licenses and run digital products. A number of projects in hand are described, and emerging trends analyzed.

\section{$\mathrm{T}$} he state of progress and the details of implementation in various countries of initiatives to share digital information resources obviously depend-apart from current investment policies to develop the information society - on many factors of a historical, social, and cultural nature that have determined the evolution and consolidation of cooperation practices specific to each context.

Before going to the heart of the specific subject of this article, in order to foster an understanding of the environment in which the trends and problems that we shall be considering are set, I feel it best to give a quick (and necessarily summary) sketch of the library cooperation position in Italy.

The word "cooperation" became established in the language of Italian librarians only toward the mid-'70s, when in the sector of public libraries-which were transferred in those years from central government to local authorities - the "territorial library systems" were taking shape: this was a form of cooperation provided for and encouraged by regional laws that brought together groups of small and medium-sized libraries, often around a system centre supplying shared services.

A few years later, in the wake of the new information technologies and in line with ongoing trends in the most advanced countries, in Italy, too, the term "cooperation" became increasingly associated with the concept of computerized library networks. The decisive impulse in this direction came from a project of the National Library Service (SBN), the national network of Italian libraries, then in a gestation stage, which also had the merit of

Tommaso Giordano (giordano@datacomm.iue.it) is Deputy Director of the Library at the European University Institute, Florence. speeding up the opening of the Italian librarianship profession to experiences underway in the most advanced countries. 1

In the ' $80 \mathrm{~s}$, cooperation, together with automation, was the dominant theme at conferences and in Italian professional literature. However, the heat of the debate had no satisfactory counterpart in terms of practical implementation, because of both resistance attributable to a noninnovative administrative culture and the polarization of the bulk of the investments a round a single major project (the SBN network), the technical and organizational choices of which were shared by only part of the libraries, while others remained completely outside this programme. Many librarians, while recognizing the progress over the last fifteen or twenty years (including the possibility of accessing the collective catalogue of SBN libraries through the Internet), maintain that results obtained in the area of cooperation are well below expectations, or energy involved. I am touching here on one of the most sensitive, controversial points in the ongoing professional debate, which I do not wish to dwell on except to note the split that came in Italian libraries following the vicissitudes of a project that ought, instead, to have united them and stimulated large-scale cooperation. ${ }^{2}$

I shall now seek to summarize the cooperation position in Italy in relation to the subject of this article. Very schematically (and arbitrarily) I have grouped the experiences I feel most signficant under three heads: SBN network, territorial library systems, and sectoral cooperation.

SBN brings together some eight hundred large, medium-sized, and small libraries (national, localauthority, university, and research-institute). The programme, funded by the central government, supports cooperation in the following main sectors:

- hardware sharing,

- development and maintenance of library software packages,

- network administration,

- shared cataloguing, and

- interlibrary loans.

The SBN is a star network with its central node consisting of a database (the so-called "index") containing the collective catalogue of the participating libraries (currently some four million relevant bibliographic titles and 7.5 million locations). To the index are linked the thirtyseven local systems, single libraries or multiple libraries, that apply the computerized procedures developed by the SBN programme. Thus the SBN is a closed network of only those libraries agreeing to adopt the automation systems distributed by the Central Institute for the Union Catalogue, the central office coordinating the programme, take part. 
From the organizational viewpoint, the SBN can be regarded as a de facto consortium (i.e., not in the legal sense of the term), even if the management bodies, participation structures, and funding mechanisms differ considerably from consortia that have been set up in other countries. In fact, libraries join the SBN through an agreement among state, regions, and universities, and the governing bodies represent not the libraries but their parent institutions. Participating libraries receive the services free, and funding for developing the systems and network administration comes from the central government, which coordinates the technical level of the project through ICCU. ${ }^{3}$ Currently, ideas are moving toward evolving the SBN into an open network system and reorganizing its management bodies: if this provision becomes a reality, the SBN will have potential for taking on an important role in developing digital cooperation.

The territorial library systems, developed especially in the central and northern regions, consist of small groups of public libraries cooperating in one or more sectors of activity such as:

- sharing computer systems,

- cataloguing,

- centralized management of purchases,

- interlibrary loans, and

- professional training and other activities.

The library systems are based on conventions and formal or informal agreements between local institutions (the municipalities) and receive support from the provincial and regional administrations. In more recent years some systems (e.g., Abano Terme, in the Veneto) have formed themselves into formal, legal consortia. The most advanced experience in this sector-for example, the libraries in the Valseriana (an industrial valley in Lombardy), which have been operating on the basis of an informal consortium for some twenty years now-have reached a high level of efficiency comparable with the most developed European situations and may rightly be regarded as reference models for the organization of cooperation. However, given their limited size, they are unlikely to achieve economies of scale in the digital context unless they develop broader alliances. It is not unlikely that these consortia, given their capacity to work together, will in the near future develop broader forms of cooperation suited to tackling current technological challenges.

Sectoral cooperation (cooperation by area of specialization) is meeting today with steadily increasing interest, though it did not fare very well in the past. Among the rare initiatives embarked upon by university and research libraries in this direction, particular importance in our context attaches to the National Coordination of Architectural Libraries (CNBA), started some twenty years ago, which became an association in 1991. The CNBA has various projects on its programme and can be regarded as an established reference point for cooperation among architectural libraries.

We should also mention one of the "oldest" cooperation projects among research libraries: the Italian periodicals catalogue promoted by the National Research Council (CNR), recently made available online by the University of Bologna. ${ }^{4}$

To complete this sketch, at least a mention should be made of the participation of Italian libraries in the European Commission's technical programme in favor of libraries. This programme, which since 1991 has mobilized the world of libraries in the European Union, not only favors and guides explosion of technologies into libraries in accordance with preset objectives, but also has the aim of encouraging cooperation among libraries in the various countries. The programme - the latest edition of which includes not just libraries but also archives and museums-has secured significant participation from many Italian libraries. Over and above the validity of the projects already carried out or under way (important as that is), this programme has been very valuable to Italian libraries in terms of exchanges of experience and of opening up professional horizons, especially as regards cooperation practice. ${ }^{5}$

\section{Digital Cooperation}

Recently, following the expansion of electronic publishing, university libraries have been displaying renewed interest in cooperation activities with particular reference to acquiring licenses and sharing electronic resources. This movement is at present in full swing and is giving rise to manifold cooperation initiatives. To get an idea of the trends under way, one may leaf through a session on database networking in Italian universities in the proceedings of the AIB Congress at Genoa. ${ }^{6}$ On that occasion a group of universities presented a "Draft Proposal of Agreement on Access to Electronic Information." The document is divided into two parts, the first defining the purposes and object of university cooperation in the sphere of electronic information. The second part indicates operational objectives for cooperation in acquiring electronic information and proposes a model contract for purchasing licenses, to which member universities are to keep. The content of this second part coincides with the recommendations and understandings signed by associations, consortia, and groups of libraries in other countries, and largely follows the indications and recommendations issued by the European Bureau of Library Information and Documentation Associations (EBLIDA), the organization that brings together the library associations of the various European countries; by 
the International Coalition of Library Consortia (ICOLC); and by other library organizations.

There is no point here in listing all initiatives under way in Italian libraries, in part because most of them are only just started or in the experimental stage. I shall mention a few only to bring out the trends that seem, from my point of view, to be emerging.

\section{Development of Digital Collections}

At the moment initiatives in this sector are much fewer and less substantial than in other industrialized countries. Among them the Biblioteca Telematica Italiana stands out: in it, fourteen Italian and two foreign universities digitize, archive, and put online works in Italian. The project is based on a consortium, the Italian Interuniversity Library Center for the Italian Telematic Library (CIBIT), supported by funds from the National Research Council (CNR) and made up of the fourteen Italian and two foreign universities that have signed the agreement. Technical support is provided by the CNR Institute for Computer Linguistics, located in Pisa.?

In this context we must also note, especially for the consequences it may have for the future growth of digital collections, an agreement between the National Central Library in Florence and the publishers and authors associations aimed at accomplishing the National Legal Depository for Electronic Publishing project, which also provides for production of a section of the Italian National Bibliography to be called BNIDocumenti Elettronici. The publishers who have signed the agreement undertake to supply a copy of their electronic products to the National Central Library in Florence. The latter undertakes to guarantee conservation of the electronic products deposited, and to make them accessible to the public in accordance with the agreements reached.s

\section{Description of Electronic Resources}

In this area the bulk of the initiatives are still in an embryonic stage. In the sector of periodicals index production (i.e., TOCs), mention should be made of the Economic Social Science Periodicals (ESSPER), a cooperation project on Italian economics periodicals launched by the Libero Istituto Universitario Carlo Cattaneo (Castellanza, Varese) to which some forty libraries are contributing. ${ }^{9}$ Recently the project has been extended to Italian legal journals. ESSPER is a cooperative programme based on an informal agreement among the libraries, each of which undertakes to supply in good time the TOCs of the periodical titles they have undertaken to monitor. The programme does not benefit from any outside funds, being supported entirely by the participating libraries, which have recently been endeavouring to evolve into a more structured form of cooperation.

\section{Administration of Electronic Resources and Licenses}

In this sphere there have been numerous initiatives recently, particularly by university libraries. One may note, first, a certain activism by university data-processing consortia (big computing centres created at the start of the computer era to support applications in scientific and then university and library administration areas). The Interuniversity Consortium for Automation (CILEA) in Milan, which has for some time been operating in the area of library systems and electronic information distribution (especially in the biomedical sector), has extended its activities by offering services to nonmembers of the consortium too. Recently CILEA, in connection with a broader programme-CDL-CILEA Digital Library-has been negotiating with a number of major publishers the distribution of electronic journals and online bibliographic services on the basis of needs expressed by the libraries in the consortium. CASPUR (the university computing consortia in Rome) is working on several projects, among them shared management of electronic resources on CD-ROM in a network among five universities of the Centre-South. CASPUR, too, has opened its services to libraries not in the consortium and is negotiating with a number of major publishers the licenses for establishing a mirror site for electronic periodicals. The University of Genoa, through CSITA, its computing services centre, has concluded an agreement with an Italian distributor of electronic services to enable multisite license-sharing for biomedical databases by institutions operating on the territory of Liguria. Very recently the universities of Florence, Bologna, Modena, Genoa, and Venice and the European University Institute in Florence have initiated a pilot project (CIPE) for shared administration of electronic periodicals, and have begun negotiations with a number of publishers.

Let us now seek to draw some conclusions from this initial, brief consideration of current initiatives:

- Initiatives in the area of digital cooperation are coming mainly from the world of university and research-institute libraries.

- No projects are big enough to achieve economies of scale, with most initiatives in hand having a very limited number of partners and often being experimental in nature.

- Projects under way do not provide for the formation of proper consortia, most likely because the legal form of the consortium is hard to set up in Italy because of the burdens involved, especially the complexity and length of the decision-making processes needed to constitute such an organization. 
- Librarians prefer decentralized forms of cooperation, partly because, shaken by experiences of the past, they fear losing autonomy and efficiency and finding themselves caught up in the bureaucracy of centralized organizations. "However, there can also be a correlation between the amount of autonomy that the individual institution retains and the ability of the consortium to achieve goals as a group". This observation by Allen and Hirshon obviously holds for Italy too. ${ }^{10} \mathrm{It}$ is no coincidence, in fact, that university computing consortia, who have centralized staff and funds available, are able to carry out more incisive actions in this sector.

- Except for the Biblioteca Telematica Italiana, no initiatives seem to have been incentivized by ad hoc government programmes or funds.

- A part of the cooperation projects concerns sharing of databases on CD-ROMs. The traditional Italian resistance to online materials would seem to be due partly to the still inadequate network infrastructures in our country; improvements in this sector might bring a quick turnaround here.

- Some initiatives in hand have been inspired more by suppliers than by librarians: the risk is to cooperate in distributing a particular product, not to enhance libraries' bargaining power. Without wishing to deny anything to the suppliers, who today play an essential part in terms of professional information too, I feel that keeping the roles clearly separate may help to develop clear, upright and mutually advantageous cooperation.

- Some major projects are being led by university computing consortia that have begun to take an interest in the library sector. The university computing consortia would indeed have some of the requirements to play a first-rank role in this sphere if they can manage to bring themselves into their most natural position, i.e., to operate as agents of libraries rather than as distributors of services on behalf of the commercial suppliers. Moreover, it ought to be clear that the computing consortia should act as partners with the library consortia and not as substitutes for them, otherwise the libraries risk limiting their autonomy of decision.

- Some attention is turning toward university electronic publishing, though at the present stage it does not seem there are practical projects for cooperation in this area.

- Finally, one has to note low initiative by libraries (compared with other countries) in developing content and in storing digital collections.

The analysis I have rapidly summarized here is the basis for an initative which has in recent months been stimulating the debate on digital cooperation in Italy. I am referring to the Italian National Forum on Electronic Information Resources (INFER), a coordination group initially promoted by the European University Institute, the University of Florence, and a number of universities in the Centre-North, which is today extending beyond the sphere of university and research libraries. The forum's chief mission is to cooperate to promote efficient use of electronic information resources and facilitate access by the public. To this end it encourages libraries to set up consortia and other types of agreement on acquisition and management of electronic resources and access to them. INFER's objectives can be summarized as follows:

- to act as a reference and linkage point and develop initiatives to promote activities and programmes in the area of library electronic resource sharing;

- to enhance awareness both at institutional political levels (ministries, universities, local authorities, etc.) and among librarians and end users;

- to facilitate dialogue and mutual collaboration between libraries and all others in the knowledge production and distribution chain, to help them all (authors, publishers, intermediaries, end users) to take advantage of the opportunities offered by the information society; and

- to maintain contacts with similar initiatives under way in other countries.

INFER has immediately embarked on a rich programme of activities which is giving appreciable results especially in terms of raising awareness of the problem and coordinating initiatives in the area. We shall here briefly mention some of the actions in hand that seem to us most important.

Dissemination of information. INFER has developed a Web site where as well as information on the Forum's activities, important information and documents can be found relating to the consortia, the negotiations and licenses, and in general the digital resource-sharing programmes in Italy and around the world. ${ }^{11} \mathrm{~A}$ discussion list for INFER members has also been activated.

Seminars and workshops. This activity is aimed at further exploration of themes of particular interest (e.g., legal aspects of license contracts, or programmes under way in other countries).

Data collection. The two main programmes coming under this heading are: (a) monitoring of Italian cooperation initiatives under way in the digital sector; and (b) collecting data on acquisitions of electronic information resources in university libraries. This information will enable the libraries to have a more exact picture of the situation, so as to assess their bargaining power and achieve the necessary support to adopt the most appropriate strategies. 
Indications and recommendations. As well as translating and distributing documents from the most important associations operating in this area (such as EBLIDA, ICOLC, and IFLA), INFER is developing a model license for the Italian consortia.

INFER was set up in May 1999 and currently has some forty members, most of them representatives of university library systems, university computing consortia or research libraries, or university professors. One of INFER's aspirations is to persuade decision-makers to develop a programme of incentives on a national scale for the creation of library consortia.

\section{Critical Factors}

As to the delay we note in terms of shared management of electronic resources, weight clearly attaches to the fact that cooperation is not very established, nor are the national structures that ought to have supported it. It would be all too easy and perhaps also more fun to attribute this situation to the so-called individualism of Italians and to abandon inquiry into the structural limitations that may have determined it.

First of all, except in very few cases, libraries have no administrative autonomy, or only very little, and with hardly any decision-making powers. This factor favors interference in decision-making processes, complicates them, slows down procedures, and strips librarians of their responsibility. One of the reasons why the SBN has not managed to generate cooperation is to be sought in the mechanisms for joining and participating in the programme. In other words, many libraries have joined the SBN following decisions taken from above, at the political and admistrative levels, and not on the basis of an autonomous, weighted assessment of attitudes, needs, and alternatives.

These experiences have augmented libraries' reluctance to embark on centrally steered national programmes. On the other hand, the low administrative autonomy they have prevents them from implementing truly effective alternative solutions, i.e., ones able to realize economies of scale.

Another factor is the administrative fragmentation of libraries. The big universities have fifty or so libraries each (often one per department). Some universities have an office coordinating the libraries, but only in very few cases does this structure have the powers and the necessary support to coordinate; more often it acts as a mediation office with no real administrative powers. In short, the result is that since (perhaps also because of a misunderstood sense of departmental autonomy) there is no decision-making centre for libraries in each university, decisional processes prove slow and cumbersome. Clearly, all this brings many problems in establishing understandings and cooperative programmes with other libraries and weakens the universities in negotiating licenses. This position, while objectively favoring suppliers in the short term, in the long term risks facing them with difficulties given an increasingly impoverished, uncertain market because of the fragmentation and the limited capacity of possible purchasers.

Another limit is the insufficient awareness, especially on the academic side, of the challenges of electronic information. In early 1999 the French daily Le Monde published an extensive feature on scientific publishing, showing how current publishing production mechanisms, while assuring a few big publishers of ample profit margins, are suffocating libraries and universities under the continuous rises in prices for scientific journals. ${ }^{12}$ The argument, immediately taken up by the Spanish El Pais and other European newspapers, met with very little response in Italy. Clearly, in Italy today, the conditions do not exist to embark on initiatives like the incisive open letter to publishers sent by the Kommission des Deutschen Bibliotheksinstituts für Erwerbung und Bestandsentwicklung in Germany, supported by similar Swiss, Austrian, and Dutch organizations. 13

The lack of an adequate national policy in the area of electronic information is probably the direct consequence of the problems I have just mentioned. In this context, however praiseworthy the initiatives, they tend in the absence of reference points and practical support to break up or fritter away. Under the Ministry for Universities there are no leadership or action bodies in the area of academic information, like the Joint Information System Committee in Britain that stimulates programmes aimed at developing and utilizing information technologies in university and research libraries. These observations are also valid for the state libraries and public libraries, too, where the central (Ministry for Cultural Affairs) and regional authorities could play a more effective part in promoting digital cooperation.

\section{Conclusions}

The picture I have presented is not very rosy. However, it does reveal considerable elements of vitality and greater awareness of the problems emerging, starting with a few representatives of academic sectors who might be able to wield influence and bring about a turnaround.

At the moment, the consortium movement to share electronic resources chiefly involves university libraries, 
but a few initiatives by public libraries are starting to appear, especially in the multimedia products sector. No specific lines of action are yet emerging at the level of the national authorities-especially the Ministry for Education and Research and the Ministry of Cultural Activities, on which the national libraries and many research libraries depend. It is likely that in the near future the entry of these agencies may be able to modify the current scenario and considerably influence the approach to cooperation. From this viewpoint, the impression is that a few consortium initiatives that have been flourishing in recent months on the part of both libraries and suppliers have the principal aim of proposing cooperation models to guide future choices.

In conclusion, we are only at the outset, and the game is still waiting to be played.

\section{References and Notes}

1. Michel Boisset, "L'organisation Automatisée de la Bibliothèque de l'Institut Universitaire Européen de Florence," Bulletin des Bibliothèques de France 24, no. 5 (1979): 231-39. For an overall picture of the debate, see: La Cooperazione: Il Servizio Bibliotecario Nazionale: Atti del 30th Congresso dell'Associazione Italiana Biblioteche, Giardini Naxos, November 21-24, 1982 (Messina: Università di Messina, 1986).

2. Tommaso Giordano, "Biblioteche tra Conservazione e Innovazione," in Giornate Lincee Sulle Biblioteche Pubbliche Statali, Roma, January 21-22, 1993 (Roma: Accademia Nazionale dei Lincei, 1994): $57-65$. For the most recent developments in the debate, see the articles by Antonio Scolari, "A proposito di SBN," Giovanna Mazzola Merola, “Lo Studio sull'Evoluzione del Servizio Bibliotecario Nazionale," and Claudio Leombroni, "SBN un Bilancio per il Futuro," Bollettino AIB 37, no. 4 (1977): 437-66.

3. Further information on SBN can be found at www.iccu.sbn.it/sbn.htm, accessed Oct. 27, 1999, where the collective catalogue of participating libraries is also accessible.
4. Catalogo Italiano dei Periodici (ACNP), www.cib.unibo. it/ cataloghi/infoACNP.htm, accessed Sept. 19, 1999.

5. There is a considerable literature on the European Commission's "Libraries Programme": for a summary of projects in the programme, see Telematics for Libraries: Synopses of Projects (Luxembourg: Office for Official Publications of European Communities, 1998). Updated information on the latest version of the programme can be found at www.echo.lu/ digicult, accessed Oct. 26, 1999. On Italian participation in the programme see: "Ministero per i Beni Culturali e Ambientali, L'Osservatorio dei Programmi Internazionali delle Biblioteche 1995-1998" (Roma: MBAC, 1999).

6. Associazione Italiana Biblioteche (AIB), XLIV Congresso Nazionale AIB. Genova, 1988: www.aib.it/aib/congr/co98univ. htm, accessed Oct. 27, 1999.

7. More information about CIBIT can be found at www.ilc.pi.cnr.it/pesystem/19.htm, accessed May 19, 2000.

8. Progetto EDEN: Deposito Legale Editoria Elettronica Nazionale, www.bncf.firenze.sbn.it/progetti.html, accessed Sept. 29, 1999.

9. More information about ESSPER may be found at www.liuc.it/biblio/essper/Default.htm, accessed May 19, 2000.

10. Barbara McFadden Allen and Arnold Hirshon, "Hanging Together to Avoid Hanging Separately: Opportunities for Academic Libraries and Consortia," Information Technology and Libraries 17, no. 1 (1998): 37-44.

11. The INFER Web page can be found on the Università di Roma I site, www.uniroma1.it/infer, accessed May 19, 1999.

12. Le Monde, 22 Jan. 1999: A whole page is devoted to this topic. See especially the article titled "Les Journaux Scientifiques Menacés per la Concurrence d'Internet." Accessed Feb. 4, 1999, www.lemonde.fr/nvtechno/branche/journo/index.html. The point was taken up again by El País, 27 Jan. 1999; see the article titled "Las Revistas Científicas, Amenazadas por Internet."

13. The letter, signed by Werner Reinhardt, DBI president, is

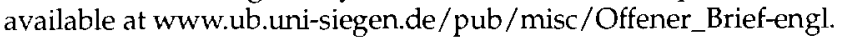
pdf, accessed Feb. 4, 1999. 